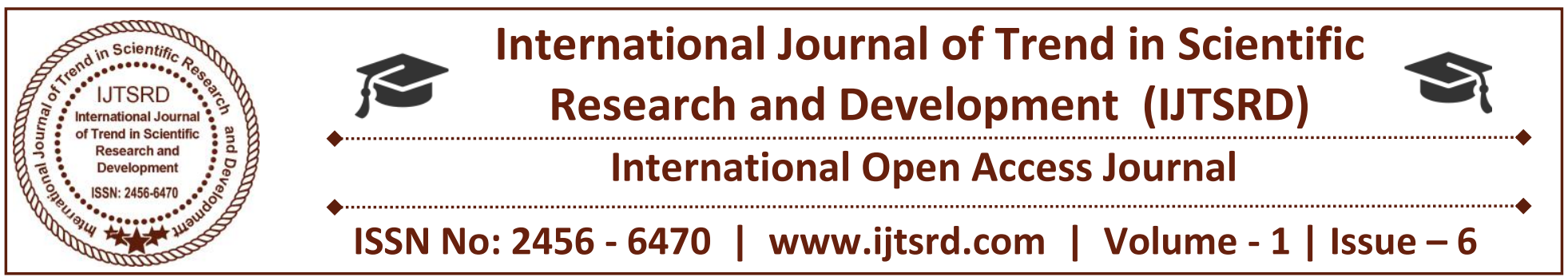

\title{
Conflict Management - A Rare Art of Modern Management in India
}

\author{
Mr. Vikas Pathak \\ Swami Vivekanand University, \\ Sironja Sagar, M.P.
}

\author{
Dr. Pramesh Gautam \\ Dean, Faculty of Management and Commerce, \\ Swami Vivekanand University, \\ Sironja Sagar, M.P.
}

\begin{abstract}
This study examined the process of handling the conflict in the world with diversified culture. Conflict is associated with every individual. Majorly it's a part of human life. Handling conflict is a most important task. The study in this research paper concentrates on the ways of handling the conflict by people and majorly by organizations. The stress is given majorly on Manager who is handling the conflict. Conflict management is an inbuilt art and no training or preparedness is required for a real modern manager in an organization. Most of the organizations are failed to recognize the true potential of associates in this diversified society of cross cultures. By following the steps written in this research paper, problem will be subsidized to a certain extent.
\end{abstract}

Keyword: real modern manager, Conflict

\section{WHAT IS CONFLICT?}

A disparity among two parties or a group is conflict. Since an individual is seeking to show their worthily attitude which results into dispute with other people. Conflict emerges from differences. It generally occurs whenever there is disagreement over once desire, lack of motivation and not following individual's values.

Conflict Is Unavoidable act. Actually due to diversity, people are different with different geography and past histories, also they different set of goals in life, due to this resulting difference is found in nature. Conflict is a part of every interpersonal relationship, whether between parents and children, brothers and sisters, friends, partners, or co-workers.

\section{DEFINITION OF CONFLICT}

Conflict is a process that arose due to disagreements over the goals to be achieved or the methods to be used to attain them. It is a condition in which two or more parties feel themselves in opposition.

\section{CHARACTERISTICS OF CONFLICT}

\section{Conflict is Part of Life:}

When two parties interact, there are always chances of conflict due to individual desires. Everybody likes to be oneself and an ambition of individuals idea needs to be implemented by all (immaterial of either its right or wrong).

\section{Conflict is Unavoidable:}

Every person has its own aura and intellectual property. Hence they may have individual differences. Conflict arises because we are human being and has a brain. Conflict can be subsidized or its degree can be minimized but cannot be stopped. Conflict exists everywhere around the world.

\section{Conflict is a Process:}

Conflict starts when we interact, when interaction begins the parties have agreement level, imbalance in 
their agreement level starts annoyance, annoyance causes conflict. So conflict is an interlinked process.

\section{Conflict Interdependence:}

As mentioned conflict is a process, so process is always interdependent and linked. Conflict arises when interaction takes place.

\section{Conflict in masses:}

Conflict occurs in individual, organizations, related groups and between different parties.

\section{Conflict is multi-dimensional:}

Conflict arrives through multiple channels in accordance with degree of seriousness and capacity.

\section{TYPES OF CONFLICT}

\section{Interpersonal Conflict:}

Interpersonal conflict arises due to disagreement between two people/parties in an organization. People think of their prestige will be diminished and self image will be lost .Every individual has it's own intellectual property and aura and conflict is caused due to differences in personality and different set of temperaments among two or more individuals.

Result of such conflicts is spoil of relationship. For example, you have decided to study more today as you have a dream to become IAS officer, but your partner want to enjoy party and watch a movie, then attainment of two goals at a same time is not possible then interpersonal conflict starts taking place.

\section{Handling Inter-Personal Conflicts? -The Managerial Action:}

Actually speaking No manager can stop a conflict as conflict arise always whenever there is people interaction. Interpersonal conflict can be subsidized. A good manager would be better to ask the associates to describe the will one party wants to execute with the other. It would be better to have no direct superior of the party is involved. Also in high conflict situations it's always advisable not to meet separately with people of either party.

To minimize conflict a good manager should take following steps:

A. Arranging Regular Meetings: The managers arrange management meetings to inform employees about new initiatives of the organization and the progress of current projects.
B. Process based working: In day to day official work the process should be developed keeping in mind the inputs received from employees. Such process should be distributed to all concerned teams. Proper training of concerned employees needs to be trained in those processes.

C. Regular Review of Job roles: Any change in process should be in line with the Job role and person. This process is regularly reviewed. A good manager must provide timely suggestions for the assigned roles.

D. Training: Manager needs to be provided training in interpersonal communication, conflict management, and delegation of authority. It is one of the essential factors handling interpersonal conflict.

E. Suggestion Box Placement: In office premises there should be a mechanism where person can put in suggestions without names written over the suggestion idea.

F. Building Relationship with Subordinate staff: Gatherings, celebrations, good working atmosphere and meeting associates at regular intervals also taking with them about their achievements and help on the problems they faced during the work.

G. Status Reporting: An associate must provide status reports to the manager and manager to his immediate superior so as to maintain pre-analysis of conflict prior any delay.

H. Awards and Recognition: A manager must get progress report about his subordinates regularly, indicating achievements, current needs and future scenario. Associates must be awarded by on the spot award or other appreciation mechanisms.

\section{Intrapersonal conflict:}

This conflict lies in person himself, intrapersonal conflict is also named as intrapsychic conflict. This conflict is develop out of your own ideas, thoughts, emotions and own values. Intrapersonal conflict occurs within you, when you internally argue with yourself about something or asking "you should have and should not have done something?". Definition wise it's a conflict which occurs in the psychological dynamics of the individual's own mind.

\section{Intergroup Conflict:}

When one group disagrees with another group then intergroup conflict occurs. A major cause for 
intergroup conflicts is competition for scarce resources. Majorly arise within groups due to difference in viewpoint or thinking towards achieving self goals. Mostly found in organizations with different set of departments, generally it is well known departments fights among themselves to prove failure is not caused due to mistake done by their department.

\section{Intragroup Conflict:}

Diversifiedness among the individuals leads to an intragroup conflict. This type of conflict happens among individuals within teams. Arose due to interpersonal disagreements or due to behavior of individual. In case degree of conflict disrupts harmony among the members in the team, then some critical advice from a different group is required for the same to be settled.

\section{EFFECTS OF CONFLICT}

Conflict Have Negative and Positive Effects

\section{$>$ Negative Effects:}

Conflict causes increased negative feelings in human being. Negative thoughts in person will lead due to conflict in day to day confusion. Conflict depletes energy of the person, when unproductive conflict strategies are used. Conflict results into fighting and causing hurt to the person. Due to negativity there are chances of loosening of bond in relationship. All this leads to never ending conflict, mutual hurt resulting into failure of relationship. Negative outcomes include inefficiency, low productivity and performance, grievances, attrition, higher absenteeism, competition, disputes, strained relationships, low morale, mistrust, low motivation and less job satisfaction and reduced coordination and cohesiveness.

\section{Positive Effects:}

After finding out a workable solution Conflict often prevents hostilities and resentments from spoiling.

If productive conflict strategies are followed, then relationship is likely to become stronger, healthier, and richer than it was before.

Positive effect causes learning with innovation, selfawareness and creativity in individuals. A good project manager in an organization already ahead of time for any conflict arising situation.

In case of conflict, parties have to convert the destructive conflict into a constructive cooperation and collaboration for the better mankind. In an organization if project manager behaves in a positive manner then more positive and beneficial result comes out from the process of negotiation.

\section{MASLOW'S THEORY OF SELF ACTUALIZATION}

Before honoring managers position to an individual in an organization, senior Management must ensure individual has a basic idea of Maslow's theory of selfactualization, as if he is not aware, he will always try to imbalance its stages. A real modern manager will always provide growth opportunities to other individuals and support in moving other individual to the next stage of hierarchy. There will always be an imbalance if fitment of Manager is not perfect and it happens generally in many cases. 


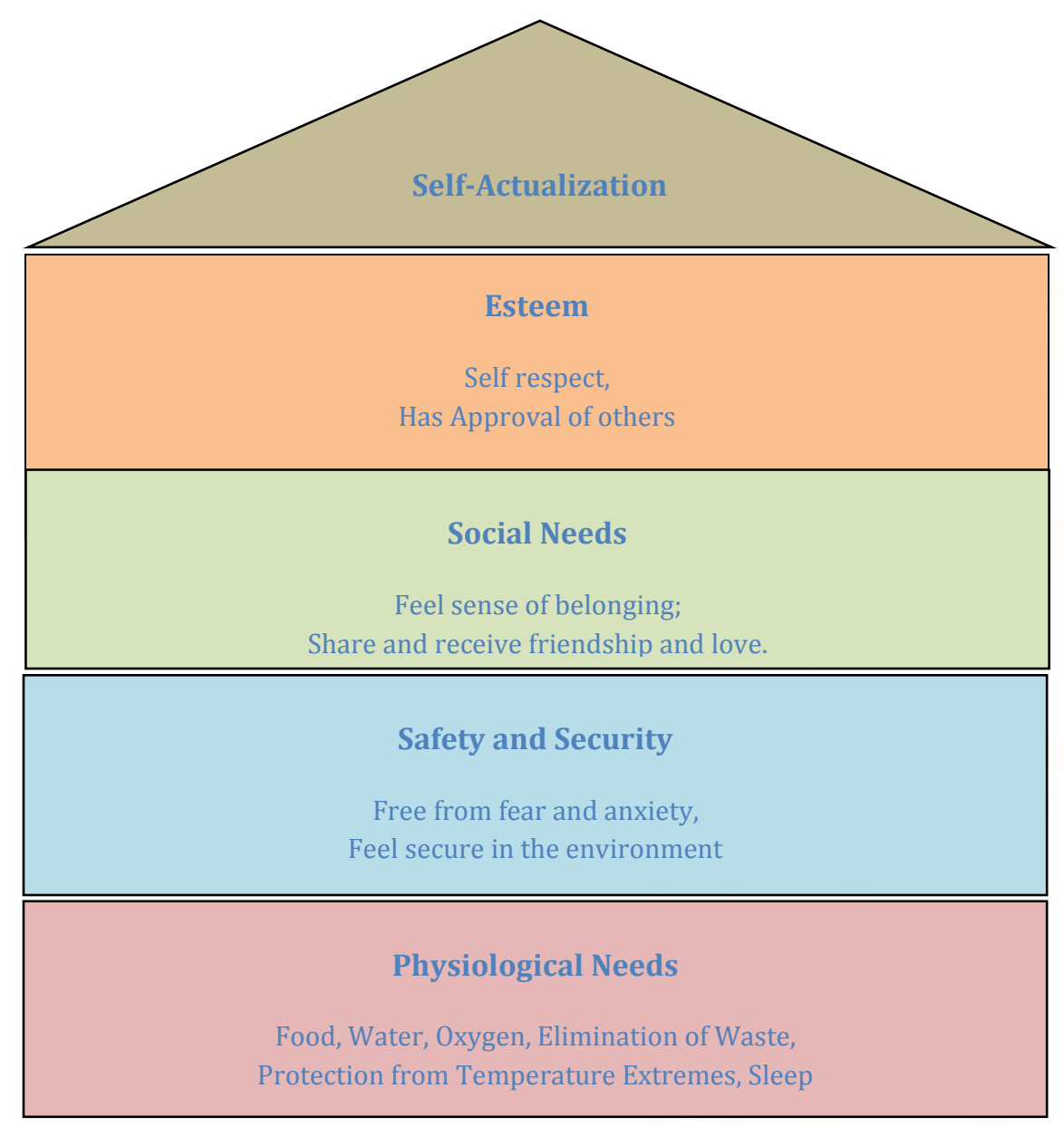

Fig: Maslow's Hierarchy of Needs

\section{DEFINITION AND MEANING}

Abraham Maslow innovated the theory of self actualization. Maslow identified five sets of human needs. The five sets of need are arranged in a hierarchy of their importance to individuals.

Maslow's hierarchy of needs includes the following:

\section{Physiological Need:}

The Basic need of human being is physiological need. Food clothing and shelter come under it. This needs lie at the lowest level of hierarchy. According to Maslow, this need is to be satisfied first and then the other needs.

\section{Safety and Security Need:}

The second need come under the hierarchy of needs. People need: Safety of life and property. Security of job, income and investment. In India most of the life passes achieving this need.

\section{Social Needs:}

A person would never prefer to live in isolation from the rest of the society or group. Human beings also feel the need to belong to a group or community. Human prefer to be loved and cared by the others $-\mathrm{i}$. e. their family members, friends, work mates, roommates, organizations and others.

\section{Esteem Needs:}

It is a behavioral need. People always feel that others should respect them. People like others should praise and give recognition to an individual and praise his qualities. Everyone like other others should have good opinion about him in society and among the people. It is the Ego needs.

\section{Self actualization needs:}

It is the hierarchy of needs. Through self actualization needs, a person feels the need to realize one's potential to the highest possible level. Very few people have such needs. This need is such a need different from common people need induce such a thing which others have not done. 
Salient features of Self -actualization theory:-

Human needs are arranged into a hierarchy. There are some needs at the lower level, and there are some other needs at the higher level of hierarchy. Lower level needs must be satisfied either wholly or partly before higher level needs emerge. In other words, a higher level need does not become active, if lower level need remain unfulfilled.

A higher level need arises before a lower level need is completely satisfied. Thus, safety needs would emerge before the physiological needs completely satisfied, and so on.

\section{Criticism of Maslow's Theory of Self- actualization:-}

1. When need is not satisfied, it becomes a motive. In Developed nations in which physiological needs like hunger and thirst are easily satisfied, physiological motives would not have much strength.

2. Human history is full of examples of people who prefer to starve rather than be humiliated. People who have satisfied their "lower" needs do not always seek "higher" ones. Maslow himself had pointed out that even if all the other needs are satisfied, people do not automatically become self-actualizers. Some people aim to satisfy "higher" needs even at the cost of "lower" needs.

\section{ANALYZING THE CONFLICTS}

This is a designated work of Project Manager and every industry should include trained and efficient project manager for any conflict handling situation. Conflict analysis should be done with self-observation and estimating the costs of conflict.

In case of multiple conflicts in any situation there is a need of its Prioritization. The conflict which is hotter should be handled first. Analysis involves brainstorming to find the present and future conflicts, prioritize conflicts with weather it is urgent or not, identify the important conflicts and also identify the stakeholders related to the conflicts.

The project managers have to listen very carefully to the subordinates and their attitude, communication and negotiation are keys to conflict management practices. Identification of conflict, generation of conflict cases, judgment execution, results analysis, cognitive feedback and negotiation between conflicting parties are the works of project manager.

\section{CONFLICT MANAGEMENT}

Conflict management is an art. It is inbuilt quality of a manager, it is the practice of being able to identify and handle conflicts efficiently and lawfully. Conflict management is a technique which is designed to reduce the negative effects of conflict and accelerate positive thoughts between parties. Conflict management involves acquiring skills related to conflict resolution, conflict communication skills, and establishing a structure for management of conflict in day to day operations.

\section{Role of Project Manager:}

Generally project managers prefer negotiation to find the best alternative solution in any conflict situation, choosing the best conflict resolution technique is the most fundamental skill of a project manager:

\section{Approaches to Handling Conflict:}

\section{Participation:}

$>$ Working together towards a solution that fully satisfies the concerns of all involved.

$>$ Root Cause analysis of issue to identify and address the underlying concerns of involved individuals.

$>$ Assertive and cooperative

$>$ The opposite of avoiding

2. Coordinating:

$>$ To Find out a mutually acceptable solution that partially satisfies both the parties

$>$ Addresses an issue more directly than avoiding, but does not explore it in as much depth as collaborating

$>$ Intermediate approach; i.e. between competing and accommodating

\section{Contest:}

$>$ By utilizing power to win position e.g., rank, position

$>$ Standing up for the individual rights

$>$ Assertive and uncooperative

\section{Considerate:}

$>$ In order to satisfy the concerns of other party neglecting your own concerns

$>$ Selfless generosity, obeying an order when you would prefer not to do the same, listening to other's point. 
International Journal of Trend in Scientific Research and Development (IJTSRD) ISSN: 2456-6470

\section{Avoiding:}

$>$ Not addressing the conflict situation and dull behavior

> Postponing the resolution of a conflict, or withdrawing from a threatening situation

$>$ Uncooperative and unassertive approach.

$>$ Pursuing neither your own concerns nor the opponent

\section{CONFLICT MANAGEMENT MECHANISM}

The result of conflict may arise as positive or negative based on its handling approach. There are four conflict resolution mechanism generally used everywhere:

A. Avoiding - keep away from any dispute and act like a descent citizen of nation.

B. Smoothing - Regularizing the impact of conflict by self designed techniques and self behavioral control is done.

C. Forcing - Physical or mental withdrawal from the conflict. Accommodating the other party's interests. Using power tactics to achieve a win.

D. Confronting - Facing the conflict directly, and working it through to a mutually satisfactory resolution.

\section{Leader vs. Manager:}

Generally now a day's organizations use the designation of leader in place of Manager. In modern management perspective a leader is next level of a manager. Organizations are not capable enough of identifying an individual is a Manager or a Leader. There are more managers but rare leaders (real modern manager). In current scenario every organization calls its managers as leaders, and this is a huge gap.

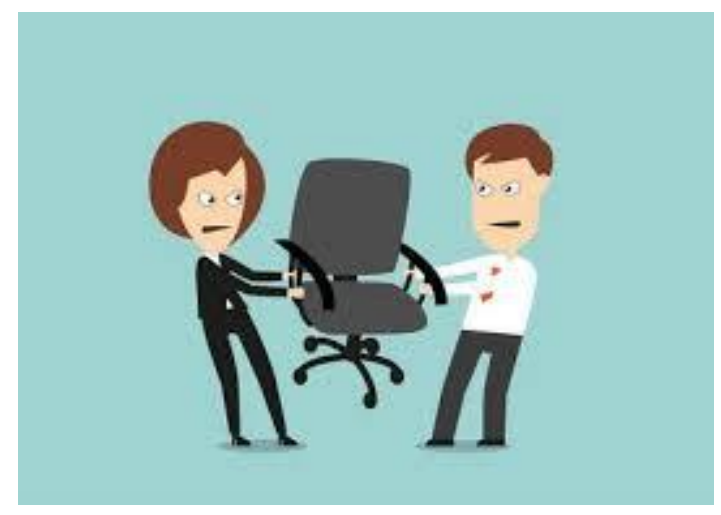

The approach can be grouped into three basic conflict management mechanisms:

\section{Win/Lose Strategy:}

This strategy may not allow maintaining good human relations because this approach eliminates the conflict by having one individual win over another. In other words, an individual achieves his goals utilizing others resources.

\section{Lose/Lose Strategy:}

This view eliminates the conflict by having both parties will lose something. Due to negative results faced by both the individuals, this technique eliminates conflicts. It can be apply in three basic ways:

Compromise: In it both the parties are asked to compromise. In such a situation third party is involved to take decision on how to resolve the conflict. This view often gives result in problem solving solution.

Arbitration: An individual must have habit of negotiation to a particular issue, rigidness in behavior causes conflict and result into ambiguity always.

Rules and Regulations: Following general rules and regulations can also resolve a conflict which may lead to lose/lose situation.

\section{Win/Win Strategy:}

The aim of technique to resolve problem without blaming on others. The following issues are involved in this approach:

$>$ Create an atmosphere of the trust among all involved.

$>$ The problem should be solved on merit and not through personal or political influence.

$>$ Listen to everybody's points of view.

This technique gives us appropriate solution that all parties accept it and, hence improves good human relations.

\section{IMPLEMENTING THE SOLUTION TO CONFLICT}

Whenever conflict arises it gives birth to creative ideas, creation of new procedures, policies, services and products. Implementation of solution for conflict is a tedious task and it involves a budget or money to provide the solution. The conflicts and its different modes of conflict resolution in projects effect individual, teams, projects and various organizational outcomes. It even impacts the economy of the nation as it involves large huge programs to run and execute.

The project manager using techniques such as communication, heterogeneity and competition can 
avoid conflicts to the opposing party to reach constructive situation. It is best practice to have a conflict management plan. The strategies must be formed to handle the conflicts and finally to decide whether:
$>$ To prevent,
$>$ To resolve
$>$ To prioritize
$>$ To act.

Large team size, functional diversity and team tenure diversity promotes constructive conflicts in projects. The implementation of solution to conflict leads to change management in the organization.

There should also be a provision of capacity building, training and different measures to handle with conflicts.

\section{A Four-Step Conflict Resolution}

Step 1: States concerns or issues

Each party should state concerns or issues one at a time uninterruptedly and the other party is requested to only listen. The listening party should prepare notes for their doubts. As a mediator, decorum is maintained and only one person speaks at a time and that each party has the opportunity to express concerns without interruption.

Step 2: Acknowledge stated concerns or issues

The acknowledgement does not necessarily imply agreement; it simply acknowledges that the concern or complaint exists. Parties may not agree with alleged concerns, but what's important is that one party believed it happened and caused harm. In this way conflict is handled.

Step 3: Take responsibility for actions

Each party must take responsibility for actions that may have been inappropriate, inaccurate or harmful.

Step 4: Make a plan for resolution

Always have ideas to keep in mind as you make a plan. Address individuals concerns always. By Brainstorming possible solutions to each concern, Choose a solution that best meets the needs of both parties. It is advisable to timely review the plan at regular intervals, also a write up for the plan should be ready and all parties are compelled to sign the agreement. This plan is intended to change the actions that caused the concerns.

\section{STRESS MANAGEMENT TECHNIQUES \\ COPING}

There are two coping technique:

\section{$>$ Emotion focused coping}

It is responding to stress in an emotional manner, especially by using defence mechanisms. It is a perfect style.

\section{$>$ Problem focused coping}

Problem focused coping strategy of facing one's problems and trying to solve them by direct action. The problem focused coping is highly beneficial. It increases a person's sense of self-esteem, control and effectiveness.

Majorly it is seen that in corporate environment, offices are compact and with much restrictions. There must be arrangements of safety and security for employees but obviously with an environment of cheerfulness. In today's corporate environment an employee is too much under phobia. He does not want to help or talk to an associate due to this phobia during office hours. Rarely is it seen use of light music while work in any of the corporates among the world. A good initiative of music is seen in huge public sector banks and public malls, same are involved in building national economy. Some of the cause of attrition in employees is due to workplace Compactness and Restrictions. Current major's taken by organizations in the name of recreation are really not efficient and these are only provisory.

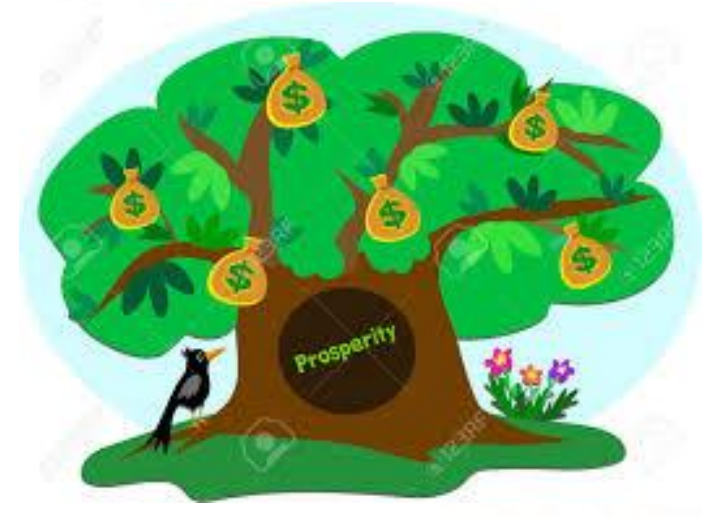

Main ways of handling stress

\section{Avoid unnecessary stress:-}

Learn how to say No -This technique may be in your personal life or may be in your professional life avoid or refused to accept added responsibility.

Avoid the people who stress you out.

Avoid hot-button topics. 
$>$ Make to-do list - analyze your schedule, and daily tasks.

$>$ Avoid negative self talk.

\section{Alter the situation}

$>$ Be willing to compromise

$>$ Be more assertive

$>$ Time management

$>$ Express your feelings instead of keeping inside.

\section{Adapt to the Stressor:}

$>$ Reframe the problems - look to the problem in positive way

$>$ Look at the big picture - analyze the stressful situation and then ask yourself how it should be long term important for me or not if your answer is no then let thing go.

$>$ Don't try to control uncontrollable look for the upside - when facing major challenges, try to look at them as opportunities for personal growth learn to forgive

$>$ Focus on positive self talk.

$>$ Accept the things you can't change

\section{Make time for fun and relaxation}

$>$ Eat a healthy diet

$>$ Reduce caffeine and sugar - by reducing the amount of coffee, soft drinks, chocolate, and sugar snacks in your diet, you will feel more relaxed and you will sleep better.

$>$ Go for a walk and watch movies

$>$ Spend time in nature

$>$ Call a good friend

$>$ Play with kid

$>$ Play with pet

$>$ Read good books and newspapers

$>$ Listen music

$>$ Watch a comedy

$>$ Set a site relaxation time

$>$ Do something you enjoy everyday

$>$ Adopt healthy life style

$>$ Exercise regularly

$>$ Do yoga

$>$ Have Enough sleep

5. Start early, work for disposal/results and timely leave for the day. Spend time with family and concentrate to achieve the Maslow's next level of hierarchy.

\section{EFFORTS TOWARDS BUILDING PEACE AND HARMONY IN SOCIETY}

Building peace is necessity of today's world. The task of building peace start within the individual. Peace is the natural state balance and harmony with joy, exploration and excitement. The world is a beautiful place with immense opportunities for learning and positive excitement. Many people believe wholeheartedly that peace needs to be built but how to start building a piece and from where to start is important in today's era.

\section{List of ideas are given below:}

Offer your help to an individual or organization involved in building peace.

$>$ Run or support a local peace festival with music, theatre, and games. Invite prominent local people; lobby them by offering your help in promoting peace.

$>$ Organize a conference.

$>$ Write an article outlining your ideas and vision.

$>$ Communal harmony is a solution to aggression and violence in Indian society. Communal harmony is an aspect of National Integration. To maintain harmony and peace introduce and learn the pluralistic nature of Indian society.

Make psychological analysis of conflicts and stress. Follow the physical and psychological strategies to come out from frustration, conflicts and stress. When the conflict and stress occurs into public aggression and violence, at the same time one should understand group or mob or public psychology and deal with it.

$>$ One should think ten times before resorting to aggression and violence publicly and its consequences.

$>$ The political, religious, social, cultural parties, institutions and organizations who for personal gain and fame encourage communal riots, aggression and violence, they should be immediately banned from functioning and the leaders of them should be immediately imprisoned.

$>$ Counselling sessions in forms of dramas, street play, poetry, songs, slogans, chart show, discussions, debates, and elocutions must be organized to bring communal harmony and peace. People in India must be given special lessons to maintain law and order and harmony and peace.

Make a new friend, later plan with him/her a peace building activity.

Talk through your anxieties about getting involved with a friend. Plan to do something, however small.

Identify one thing you are good at and see how to use it to build peace, locally, nationally or wider. 
Write a letter to someone in authority about a specific problem: put a possible peace building solution.

$>$ Build or join a supportive network organization with an interest in peace building close to your own

$>$ Put interested people in touch with existing organizations or each other.

$>$ Have a neighbourhood party or picnic to celebrate a happy event. Encourage conversation about peace building there.

$>$ Never compare yourself with others, as every individual has an intellectual property. Comparison is a first stage rising conflict among individuals. An individual must have a habit of self-sacrifice in certain matters.

$>$ Do not entertain individuals who believe sitting long duration in office without work to show they are dedicated. Smart working and agile methods must be adopted.

$>$ Before hiring an individual in organization, manager must have a capability of properly utilizing the resource. There should not be hire and fire policy of the organization. If individual do not perform then management is held responsible for the same.

\section{NEGOTIATION SKILLS}

Some of the managers involve themselves too much in their work and their expectation with others remains same, as every individual has its own intellectual property so it is not feasible that other individual act or think in a similar manner. Due to pressure and commitments involved manager ignores his social responsibilities and feels his office as his life, but reality is different. A modern Manger must balance his life and must be a cheerful personality. A manger this time must act as a leader, a leaders has an armory equipped with a skill which is known as negotiation.

\section{CONCLUSION}

Different personalities deal conflict in different ways. Conflict resolution is a managerial art, It becomes essential for a manager to handle conflict in order to come to a conclusion that what is a suitable remedy to convert a conflict to a regular situation. Mostly a manager must have an art to find out the fitment of an individual by analyzing his background based on a normal talking interaction prior to designation of tasks.
Conflict management is both formal and informal. Outcome is possible by both of the ways. A process based organization has a system in place, in huge programs the characteristics of conflict such as input, transformation, result, purpose, boundaries and feedback matters. A better Conflict management system is right based, interest based and negotiation based. Positive conflict management results in to an innovation and better performance. Organizations goal must be to handle conflict management as their core competency. One important thing is conflict management in organizations must be an ethical task.

In Organization's across the world quality of a Manager is degraded to such a level in which, he is not capable of analyzing what is right and what is wrong, justice to an individual is rare. In today's scenario a manager is only a representative of organizations policies, he has no right to decide what is right or wrong. In such a conflicting situation most of managers fail. A real Management is an inbuilt quality of a manager; it cannot be inducted through courses or trainings, because trainings are only guidelines. Organizations do not have suitable manpower of real modern manager, who can identify "potential management individual" working in his organization. Mostly across the world it is seen there is lot of trouble to implement a good thing or a good management practice, the same is only due to fitment issues. An individual capable of performing the desired task is knowingly not given that task by management authorities. There will be prosperity among developing nations by resolving these fitment issues. Therefore Conflict Management is termed as a rare art in Modern Management.

\section{REFERENCES:}

1) A Review of Conflict Management Techniques in Projects Goparaju Purna Sudhakara. The ICFAI University Group, Hyderabad, India.

2) Various Internet Sources.

3) Leadership and Conflict Management Style among Indian Managers Jaypee University

4) A Study on Stress Management and Coping Strategies With Reference to IT Companies. PG college Hyderabad.

5) Conflict Management in Organization: Gender Perspective Department of Public Administration University Awka.

6) Conflict Management System and Democracy in Multinational Societies Nigeria.

7) conflict management styles of workers dr. navpreet singh sidhu ludhiana panjab. 